\title{
Representation of Aloneness in Forever Alone Guy Comic Strips
}

\author{
Pricillia Chandra $^{1}$, Ribut Basuki ${ }^{2}$ \\ Depaartment of English, Petra Christian University, Surabaya, INDONESIA \\ e-mails: Pricillia_cb@hotmail.com; rbasuki@petra.ac.id
}

\begin{abstract}
This study aims to discuss the representation of aloneness in Forever Alone Guy comic strips. The purpose of this research is to find out how the meaning of aloneness is constructed in the representation of Forever Alone Guy through the theory of representation described by Stuart Hall $(1997,2013)$. In the theory suggested by Hall, it is described that there are two ways to be done in creating representation. Those ways are through language/sign and mental representation. The mental representation is the only way used in this research with a reason that this analysis focuses to the stigmas attached to the concept of aloneness. The analysis shows that the construction of meaning is done through embedding clusters of negative stigmas to the three entities: single, alone and lonely. Thus, through the analysis, it can be concluded that the dominant meaning which represents being single and alone as the 'imperfect' condition plays an important role in the construction of the meaning.
\end{abstract}

Keywords: Representation, Dominant meaning, Singleness.

\section{INTRODUCTION}

The word 'meme', or as in the media world, 'internet meme', is a phenomenon that spreads from one person to another through the online media. There are some kinds of memes like rumours, phrases, images, audio or even video files. The development of internet memes is rapid and a lot of people are enjoying it as one of entertainment sources. There is also a meme's type called comic spin-off in which one of the characters is Forever Alone Guy (FAG). This character becomes the main character discussed in this paper. This character is considered as "one of the first major rage comic spin-off characters to be creat[o]r after the original Rage Guy, which first sprang up on 4 chan in 2009" (Kip, 2010). By September 2010, there were over 23,000 images for "Forever Alone" on Funny Junk and over 50,000 on Tumblr (Kip, 2010). Besides the forever alone character, there are some other characters such as Rage Guy, Mad Troll, Are U Kidding Me, Ultra Gay, Whyyy, Cuteness Overload, Cereal Guy, etcetera.

Every comic which uses each character as the main character has the same basic plot, in which the main plot of the story is described in the first three panels and then the character's countenance is zoomed in the fourth panel to emphasize its emotion. Besides in form of comic strip, this character is also used in a form of an image and its caption (known as meme) which caption is functioned as a short explanation to the images.
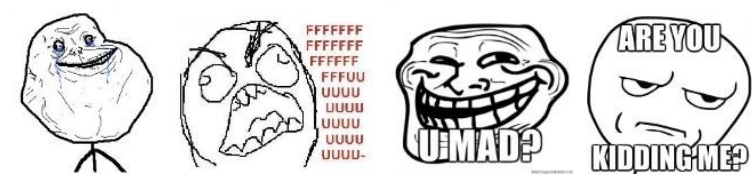

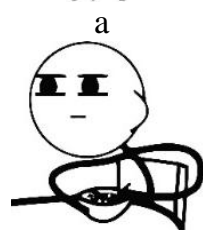

$\mathrm{b}$

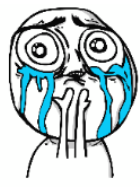

f

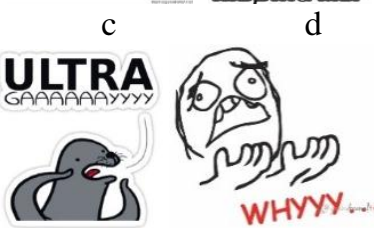

h

Picture 1. (a-h): a. Forever Alone Guy b: Rage Guy c: Mad Troll d: Are u kidding me e: Cereal Guy f: Cuteness Overload g: Ultra Gay h: Why U No?

The thing that makes each character interesting is that each character is used to represent something. Forever Alone Guy (FAG), for instance, is used to represent the life of single and alone people. The representation itself is drawn by attaching some entities that support the 'concepts' embedded through the text. The concepts embedded are built from certain stigmas that are believed and practiced in the society. Thus, it can be said that meme is not only a source of entertainment, but it is also the 'mirror' of meanings and 
beliefs that are circulated among the society. One of meanings that can be seen is from the 'meanings' constructed from the concept of aloneness.

Therefore, to find out the 'meanings' that are circulated among society about aloneness, the representtation of FAG is used as the text. Furthermore, the mental representation here is used as a tool to analyse the representation and also the 'meanings'. Mental representation is how human forms concept for things they can perceive like people or material objects. For instance, when in mind they think about a chair, they can describe what chair looks like from the representation drawn in their mind. Mental representation is not always used for concrete things, but sometimes it can be used to represent abstract things that human cannot describe in any simple way like see, touch or feel. One of the examples is love. When describing about love, a person usually cannot explain love with concrete thing, although it is true that abstract concepts such as love, hate and friendship can be represented symbolically. Whether it is concrete or abstract, concepts or meanings can be understood from analysing it through a system of representation.

Therefore the system of representation is needed here to cluster, arrange, organize and classify concepts, and establish complex relation between them. In this system, sometimes, one thing that can be done is by using "the principle of similarity and difference to establish relationships between concepts or to distinguish them from one another" (Hall, 2013, p. 3). In a book entitled Representation, Hall gives the example from the similarity and difference of a bird and an airplane. In some sense, bird and airplane are the same because both of them can fly. However, the differences are drawn when bird and airplane are seen from the perspectives of how they are made. Bird is a part of nature while airplane is man-made object. Therefore, to justify the concept whether bird and plane are the same or not, the tool that can be used is finding the similarities and differences from both objects through organizing the concepts, then classify those concepts to the conceptual system. Then, it can be concluded that bird is different from plane because the differences found are more than the similarities. From the conceptual system used in this research, or as it is often called as the mental representations, I can examine the meaning and also its construction from FAG comic strips. Moreover, because the data used mostly are in Bahasa Indonesia, I will translate the language to English and put it beside each picture.

As an assumption, I would say that FAG is represented negatively in most of FAG comic strips that I collected. In the discussion of mental representation above, I have stated that one thing that can be done to find the construction of meaning in a text is by finding the similarities and differences in the text discussed. When I use this tool to examine FAG comic strips, I find that negative meaning is often embedded to the concept of aloneness which is constructed from some mental representations represented in the text. This concept can be divided into three: single, alone and lonely.

\section{Concept of Singleness}

Single is a condition when a person is - intendedly or unintendedly - not involved in a romantic relationship. Dictionary.com defines single as "unmarried" and "pertaining to the unmarried states" (2016). Although the dictionary gives definition based on married state, here I would like to emphasize that the representation drawn in these comic strips for 'single' is more into whether a person is in a romantic relationship or not. If a person is in a romantic relationship, then, he is not single. However, the one who can be said as single is a person who is not involved in any romantic relationships.

The first concept built in the representation of FAG is as a single. In the data collected, there are some strips that represent FAG as a single in a negative way. There are three concepts constructed in this point, which draw 'single' as those who desperately need to be in a relationship, unattractive and coward.

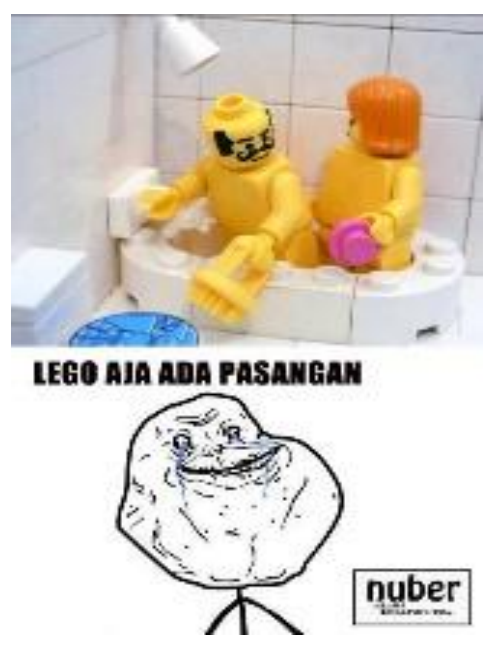

Panel 2: Even Lego has a girlfriend

Picture 2. "being single"

Firstly, FAG is represented as a single who desperately needs to be in a relationship. The comic strip above is an example of how the comic maker represents single (person) as someone who desperately needs to be in relationship through the comparison to another object. In the example above, FAG 
is compared to a couple of Legos, and behind the picture, there is a caption of "even Lego has a girlfriend". Hence, it can be seen that actually FAG is represented negatively as a single who is really "odd" if compared to the rest of the society. That is because he is still single when almost the rest of the society are in relationships or at least have someone to be loved.
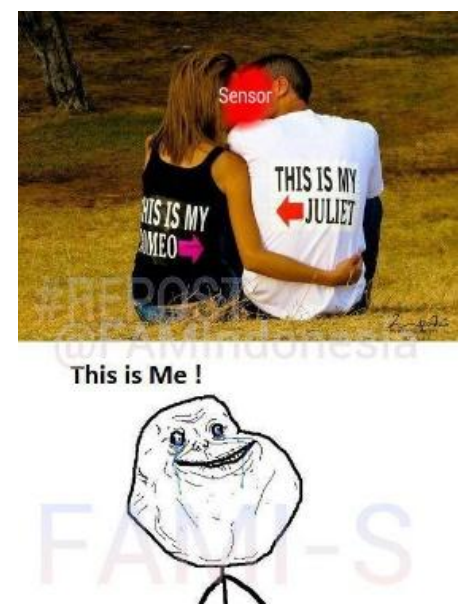

Picture 3: "being single"

The urge to be "in a relationship" can also be seen in picture three above. In the first panel of that picture, there is a picture of a couple who are kissing, and in their t-shirts, there are the statements of "this is my Romeo" and "this is my Juliet" which the arrows point to the boy and the girl. However, in the second panel, there is a picture of FAG who is alone and says, "this is me!" which indirectly points to himself and his aloneness. The negative representation that can be seen here, is drawn from the comparison between a couple who are in love and a single who feels sad because he does not have a girlfriend.

The stigma attached to single person as someone who has "the urge to be in a relationship" results from the "identity thread" that s/he encounters in his/her surroundings. In Indonesian context, especially in Javanese culture, there is a stigma which says that "singles" are those who can be described as 'inferior,' 'emotional,' 'childish,' and 'getting angry easily' (Septiana \& Syafiq, 2013, p. 74). The fear of these kinds of stigma indirectly makes a single seen as someone who desperately needs to be in a relationship. As a matter of fact, if s/he does not make an effort to be 'out' of his/her singleness, s/he will be threatened by the stigmas that soon enough, will be attached to him/her.

Moreover, Indonesian society is well known as the collectivist society - a society which suppresses its members to hold on the norm and cultures tightlyand one of the norms is to be married when it is time.
When a person is considered old enough to be married, then his/her family and friends will encourage him/her to get married as soon as possible (Hurlock, 1980 in Septiana \& Syafiq, 2013, p. 72). If this person gets married not so long after, then everyone around him/her will be happy and s/he will be accepted as a "normal" member of a society. However, if this person fails to do so, he/she will be labelled as "abnormal" (Septian \& Syafiq, 2013) and still becomes the outsider in the circle of "normal" member of society. The action of 'labelling' that is often done by society, pushes the singles to find themselves life partners, so that they will be accepted in the society normally and prevent themselves from the labels that they do not want to receive.

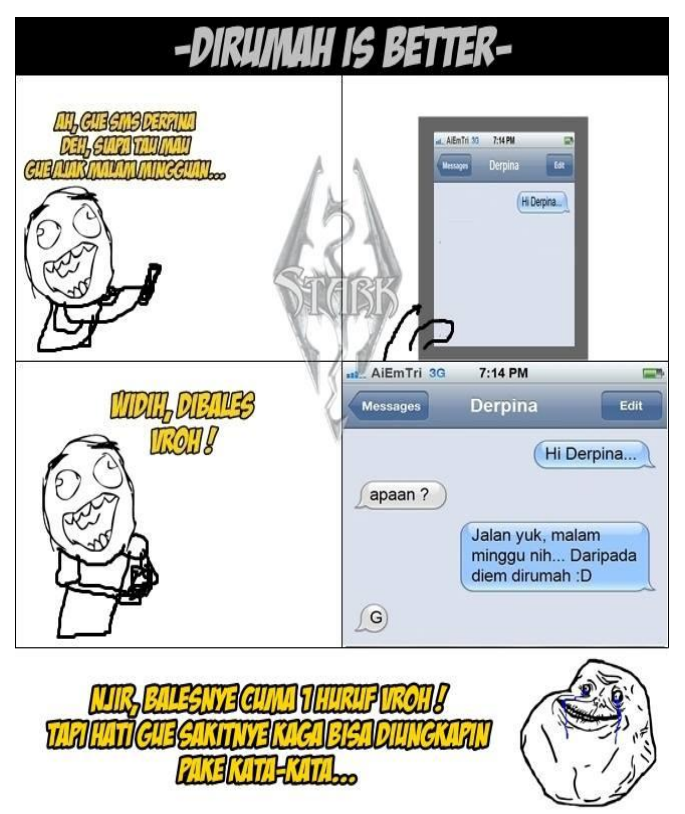

Title : Staying at home is better

Panel 1: $A h$ [interjection], I will send a message to Derpina. Who knows she wants to go out with me on this weekend.

Panel 2: [screen] Hi, Derpina.

Panel 3: Widih [interjection], she replies my message!

Panel 3: FAG: Hi Derpina | Derpina: What's up? | FAG: Let's hangout. It's Saturday night, so, it's better than just staying at house.| Derpina: No.

Picture 4. "being single"

Secondly, FAG is represented as a single who is unattractive as it can be seen in the comic strip above. In most of strips, FAG is represented as someone who is always rejected by the others, especially by those who they like. In picture four, readers can see FAG's effort in inviting Derpina to go out with him. However, Derpina only replies with short answer like "apaan?" [what?] and " $G$ " [no] which indicates that Derpina is not interested in him. Derpina seems to be rude, and seems not to be bothered in trying to be polite when rejecting him. 
Moreover, FAG is also represented as unattractive because of his/her physical appearance.

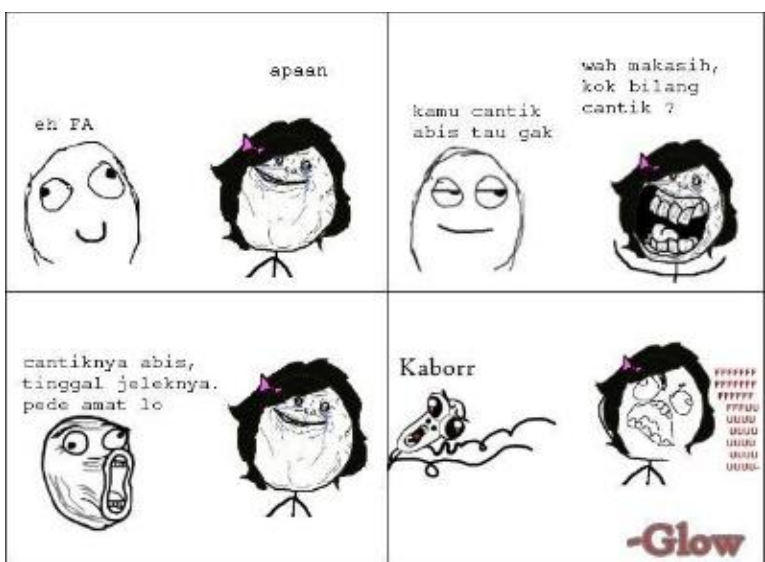

Panel 1 : Derp: $e h$ [interjection] FA [Read: forever alone] FAG: What's the matter?

Panel 2 : Derp: Do you notice that you're beautiful? | FAG: Wah [interjection], thank you. Why do you call me beautiful?

Panel 3 : Derp: The beautiful part runs out; the ugly side is left. You're too confident! | Derpina: *speechless*

Panel 4 : Derp: Escape |FAG: [swearing]

Picture 5. "being single"

In picture five above, readers can see that at first Derp appreciates FAG's beauty. After she is being appreciated by Derp, she looks so happy and says "why do you call me beautiful?". This kind of expressions indirectly shows that FAG is actually aware of her own physical appearance, and it is rare for her to be called as "beautiful". Moreover, at later panels, readers can see that actually Derp is trying to mock her by calling her "beautiful" first before he labels her as "ugly" and "too confident".

The image of "unattractive" that is attached to FAG is in line with what is stated by one of respondents in a research done by Ema \& Syafiq (2013). In one of the extracts, she said, "Ya itu sih katanya gini, ah perawan tua, gak laku (tidak laku), gitu" [They often say that I am a spinster. I am not in demand.] The label of "not in demand" or in Bahasa, gak laku, that is attached to the respondent is actually a kind of comparison of single and a thing that - because of several reasons - is not saleable. This kind of comparison gives a label to a single as having no quality to win someone's heart, whether it is physiccally, emotionally and behaviourally. With this kind of label, a single is seen as someone who is not attractive or not desirable in some ways.

Moreover, we can see how Derp (in picture five) shows his cruelness to FAG. This kind of cruelness also represents the real situation of how single people get undesirable treatments from the people around him/her. One of the undesirable treatments is by getting the labels itself. There are so many labels attached to single people such as perawan tua [spinster] or perjaka tua [old bachelor], too emotional, or too inferior (Tioso, 1991, p.20-21).

Thirdly, single is represented as someone who is a 'coward' and one of the examples can be seen as below,

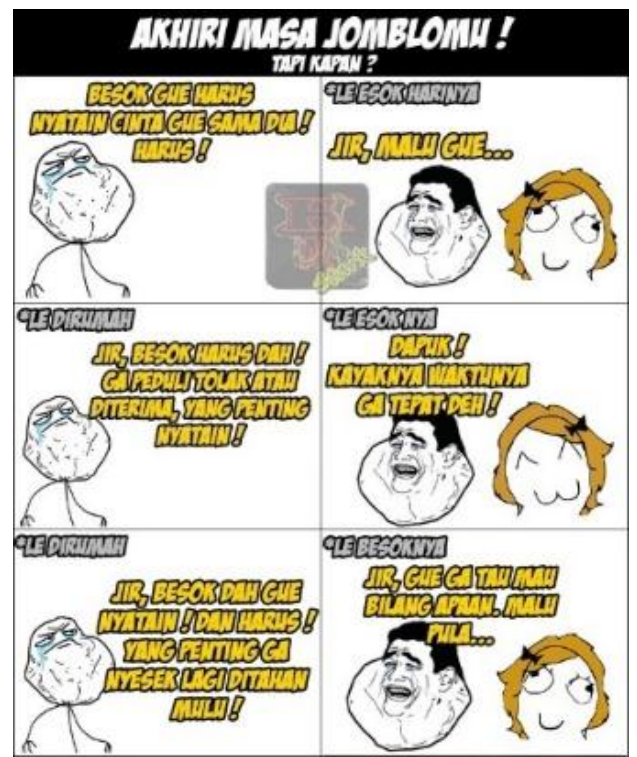

Title : End your single status! But when?

Panel 1 : FAG: Tomorrow I must confess to her! I must!

Panel 2 : [text] *I, the next morning. FAG: jir [swear], I'm too shy.

Panel 3 : [text] *I, at home. FAG: jir [swear], tomorrow I have to! I don't care whether she says yes or no. I must confess!

Panel 4 : [text] I, the next day. FAG: Dafuk [swear], I think it is not the right time.

Panel 5 : [text] *I, at home. FAG: jir [swear], tomorrow I will confess and it must! It's better than just suck my feeling up forever.

Panel 6 : [text] *I, the next day. FAG: jir [swear], I don't know what to say. I'm too shy.

Picture 6. "being single"

In picture 6 , readers may think that FAG is a determined person, judged from how he swears that he will confess to the girl he likes. However, at later panels, readers will get the impression that actually FAG is too coward just to confess his feeling. This kind of stigma is also drawn in the next picture as below.

In picture 7, readers can see that there is a monologue of a boy who tells about a girl that he likes. However, he states that the girl that she likes often tells him about her feelings to another boy. This kind of plot shows the impression that FAG (represented by the 
boy) is actually a coward, because he cannot express his feeling to that girl, or even win her heart. Thus, from these two comics, reader will get the impression that a single is actually a person who is too coward to state his/her feeling. This kind of stigma also creates the image that single is actually cupu (slang), or unable to do anything.

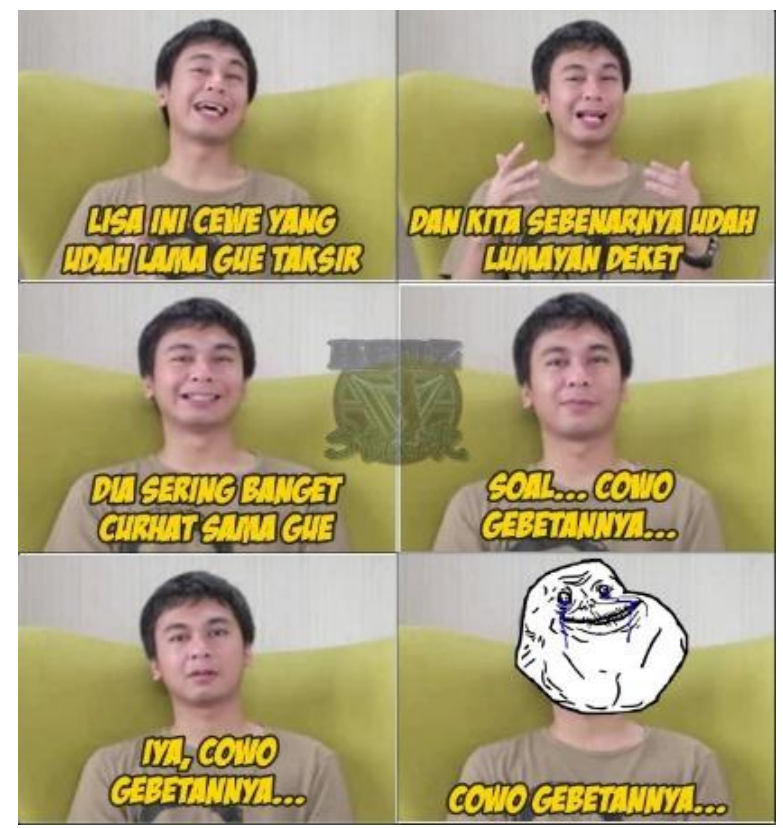

Panel 1: [boy] Lisa is the girl that I have admired for too long.

Panel 2: And we are closed already.

Panel 3: She often tells me about her feeling.

Panel 4: About... About the boy that she likes.

Panel 5: Yes, about the boy that she likes.

Panel 6: The boy that she likes.

Picture 7. "being single"

The representation of a single as someone who is 'coward' differs from the side of male single and female single. In the case of male single, their 'cowardice' can be seen as the reason why he stays single. Sometimes, a male single is also seen as someone who is less mature, that is why he is not ready for having a relationship or involved in a marriage. However, in the case of female single, people will pay more attention to her character which is too heavily unsociable. In Indonesian context, there is an assumption which states that a woman who stays single does not have the capability to socialize with others, closing herself from the outside world, although actually, she does not intend to do so (Septiana \& Syafiq, 2013, p. 75).

These concepts build negative representation of FAG as a single who desperately needs for love, and who is unattractive and coward. These kinds of perspectives fit the 'belief' that "singles" are seen as lesser and incomplete people than those who are in relationship.
They are often judged as too inferior, selfish, less mature and responsible compared to those who are not single ("Single", 2004).

To sum up, in this concept, I find that there is a negative representation of FAG character as a single who desperately needs for love, unattractive and coward. Up to this point, I can conclude that the mental representation of "single" and "being single" itself, are embedded through the similarities of negative representation.

\section{Concept of Aloneness}

Alone is a condition when someone does not have companion or does not belong to any group or community. Based on dictionary.com, alone is adjectively defined into three meanings: first, "separate, apart, or isolated from others"; second, "to the exclusion of all others or all else"; third and finally, "unique; unequalled; unexcelled" ("alone", 2016). This point can somehow be said as the continuation of the first point. That is because in one sense, being "alone" here is caused from the first point itself, which is being "single".

In the text itself, there are some strips that represent FAG negatively from the perspective of being 'alone'. There are three ideas that built the stigma of "alone" in this text: isolated, unpopular and at loss.

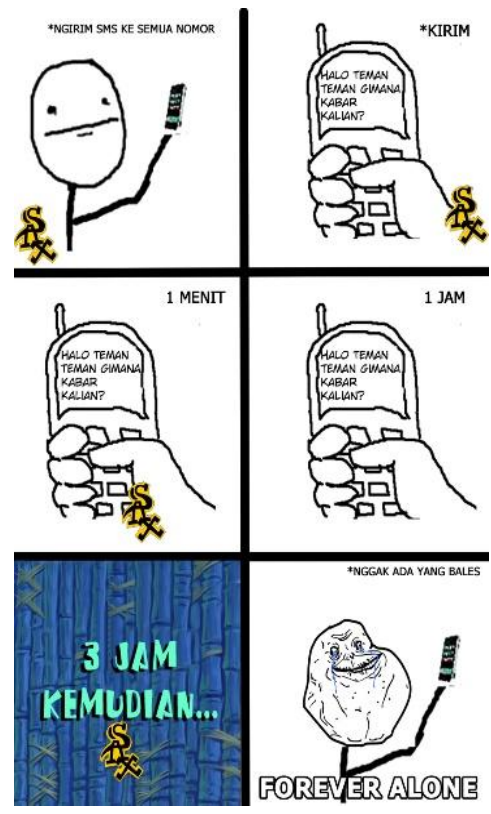

Panel 1: *sending messages to every numbers*

Panel 2 : [on-screen] Hi guys, how are you? *send

Panel 3 : [on-screen] Hi guys, how are you? *one minute

Panel 4 : [on-screen] Hi guys, how are you? *one hour

Panel 5 : 3 hours later.

Panel 6 : *no one replies. FOREVER ALONE

Picture 8. "being alone" 
In picture 8 , it can be seen how FAG is represented as an alone person who is isolated from the others. The stigma of aloneness in this comic strip can be seen from how FAG is represented as a person who tries his best to get the attention from the others. He does it by sending all numbers in his contact a message, asking them "how are you?" However, no one in his contact numbers replies to his message. From this plot, I can say that actually FAG is represented as a person who is left out from the society and has never been acknowledged by the others, and it creates the impression that everyone ignores him.

This kind of representation is in line with the perspectives attached to singles in Indonesia. Tioso (1991) wrote that one of the behaviours of (female) singles is trying to get attention from guys with excessive behaviours and it causes the others around her feel disturbed and uncomfortable near them. This kind of stigma seems like an overgeneralization because not all singles have the same characteristics as described here. However, this kind of stigma or label is what is attached to the singles, and people feel the same way toward singles. To strengthen this point, the second evidence is used as below,

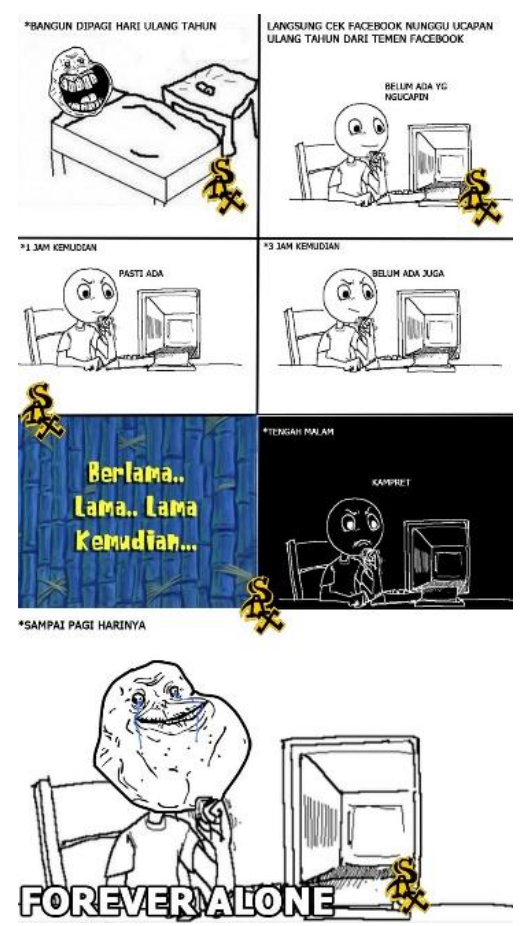

Panel 1: *wakes up in the morning of my birthday

Panel 2: checking Facebook account, waiting for someone who congratulates his birthday. [text] No one congratulates me yet.

Panel 3: *one hour later. [text] There will be one.

Panel 4: *three hours later. [text] There is none yet.

Panel 5: Many hours later.

Panel 6: *Midnight [text] Kampret (translated: swearing)

Panel 7 : *the next morning [text] FOREVER ALONE.

Picture 9. "being alone"
From picture 9, it can be seen that FAG is represented as someone who is unpopular because no one congratulates him or even just notices his birthday. From this kind of representation, I can say that FAG is represented as someone who is not popular because no one seems to care, even on his special day. This kind of representation is contradicted from what usually happens to the other characters in rage comic such as Derp. Derp somehow represents someone who is popular and needed by the others, seen from his behaviour and how the other characters treat him.

This kind of representation shows the perception that singles are those who cannot mingle with others really well because of some reasons. Therefore, because of their inability to mingle with others well, they are treated as someone "unpopular," and are not worth to get attention from the others. Moreover, this kind of representation mirrors the condition of how singles are seen as "minority", in which they do not belong to the society because of their 'incompleteness'. Due to that condition, they are treated as the outsiders in the community.

Lastly, FAG is also represented as a guy who is "at loss". In some strips, this character is often drawn as someone who misses his loved one.

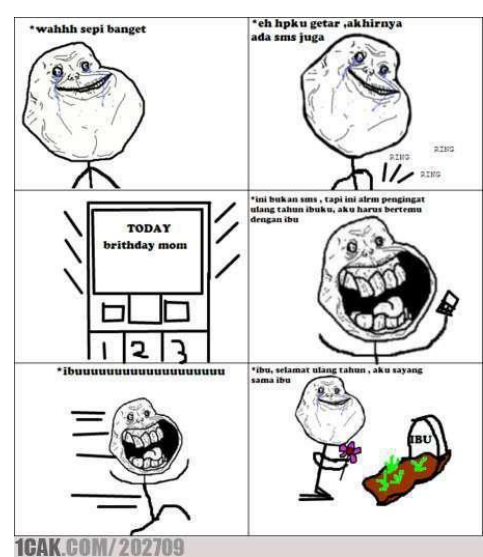

Panel 1: *FAG: wahh [interjection], it's too quiet

Panel 2: *FAG: eh [interjection] my phone vibrates. At last, there is someone who texts me.

Panel 3: [on-screen] TODAY. Mom's birthday.

Panel 4: *FAG: this is not a message. This is a reminder for my mother's birthday. I have to meet my mom.

Panel 5: *FAG: mommm!

Panel 6: Mom, happy birthday. I miss you.

Picture 10. "being alone"

In the comic strip above, readers can see how FAG reacts to his phone's vibration. $\mathrm{He}$ is so happy because he thinks that there is someone who sends him a message. After that, he realizes that it is actually a reminder of his mother's birthday and he rushes to 
his mother's funeral to congratulate her. This plot somehow draws the impression that FAG feels so alone, until his mother's presence still becomes something that is important to him. In this strip, readers can also see that FAG has no one to talk or even share his feelings.

This kind of representation mirrors singles in Indonesian society. Singles are seen as those who are too attached to the uncomon things or something that is not significant on their age like games, comic, anime, etcetera. Therefore, when s/he loses that "something", s/he will be so weak and weepy, and s/he thinks that $\mathrm{s} / \mathrm{he}$ are the one who suffers most. Moreover, this kind of representation also indicates that singles have a very limited circle. It makes them considered as 'inferior' but also 'selfish' at the same time since they cannot expand their circle and seem to be attached to their own small circle.

Up to this point, I can say that FAG is represented as someone who always feels alone because he is always isolated, unpopular and in loss. Therefore, I can conclude that the mental representation of "alone" and "being alone" here, are embedded with the similarities of negative representation from the text.

\section{Concept of Loneliness}

The third mental representation is from the concept of lonely. This differs the previous points which are "single" and "alone". Single and alone describe more to the condition or state, but lonely describes the feeling of FAG because of the state. Lonely is "[the condition which] affected with, characterized by, or causing a depressing feeling of being alone; lonesome" ("lonely", 2016). Therefore, there are some comic strips that are used on this point to examine the representation of the mental process of "lonely" itself.

This representation is in line with what is described in the research described by Septiana \& Syaufiq (2013). One of the psychological aspects caused by society's pressure is the feeling of loneliness itself. The pressures that are given by the society affect the feeling of "incompleteness" felt by most singles. That is why, the sense of incompleteness creates a desire in most singles to get someone to secure themselves from the "identity thread" (p.78). There are three things expressed by FAG when reacting to his loneliness. Those are imagining to be in love, comforting himself and pretending to have a companion.

The first expression represented by the comic strip is how FAG often imagines himself to be in relationship as below,

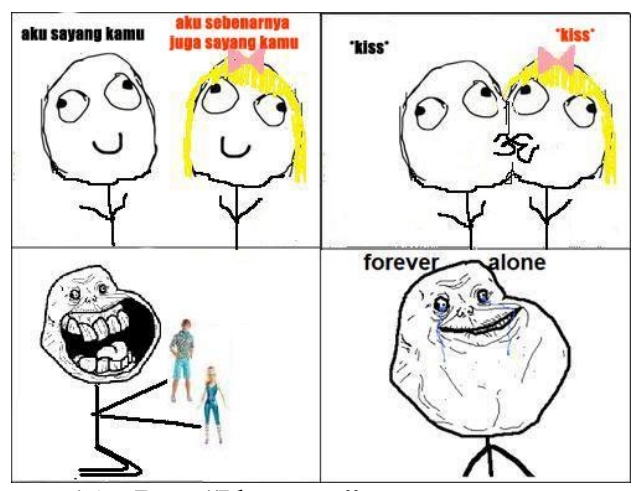

Panel 1: Boy: "I love you"

Girl: Honestly, I love you too

Panel 2: Boy \& girl kiss

Picture 11. "being lonely"

In picture 11, at first readers may think that there are love birds who are in love and then they kiss. However, in the later panels, readers see that actually the scenes are created by FAG who really wishes to be the man (Barbie) that he is playing with.

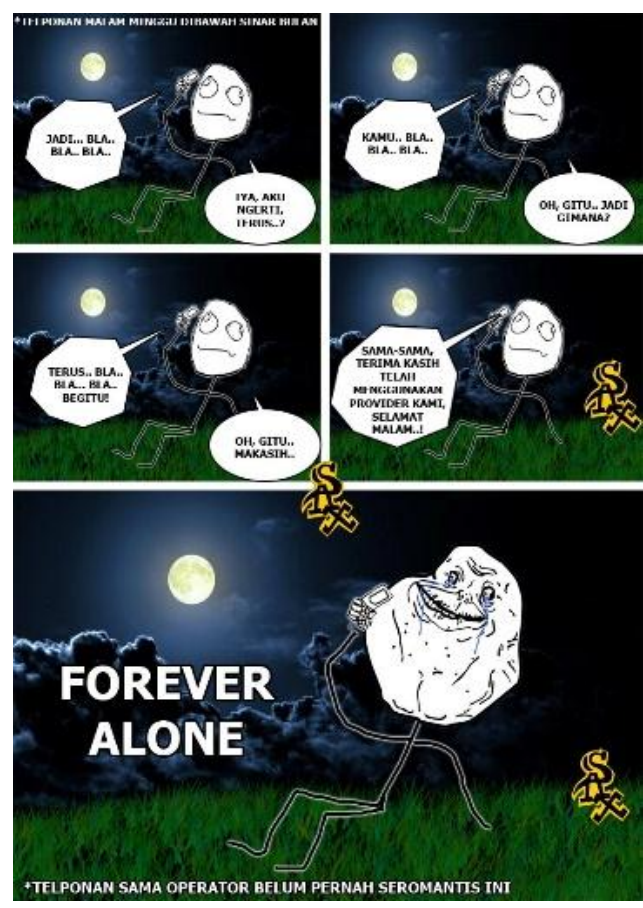

Panel 1: *calling someone on Saturday night under the moonlight [balloon text] Someone on the phone: So, bla, bla, bla |FAG: [balloon text] yea, I know. Then?

Panel 2: [balloon text] someone on the phone: You're bla bla bla | [balloon text] FAG: Oh, I see. Then what should I do?

Panel 3: [balloon text] someone on the phone: Then, blab la bla |[balloon text] FAG: oh, right. Thank you.

Panel 4: [balloon text] someone on the phone: You are welcome, thank you for using our provider. Good evening.

Panel 5: Forever Alone *calling phone officer has never been this romantic.

Picture 12. "being lonely" 
As seen in picture 12 above, FAG is represented negatively from the "perspectives" embedded into it. In picture 12, the feeling which is drawn to FAG as someone who feels lonely, is more explicit. As I stated before, FAG is often represented as a dreamer who wants to be in a relationship, and in picture 12, readers can see how this character imagines the phone officer as her girlfriend by calling her romantically under the moonlight with a happy expression as if he is falling in love with someone who calls him.

This kind of representation somehow shows the desperation felt by most singles. They really want to get a companion, yet they do not know what to do. This kind of feeling indicates how they are unable to fight the stereotype and label attached to them. Furthermore, this kind of representation also shows that actually, most of singles agree with the "truth" set by the society. The "truth" states that being in a relationship is a perfect condition, while being alone and lonely is a frustrating condition that should be pushed away.

Secondly, the loneliness is often represented by how FAG comforts himself.

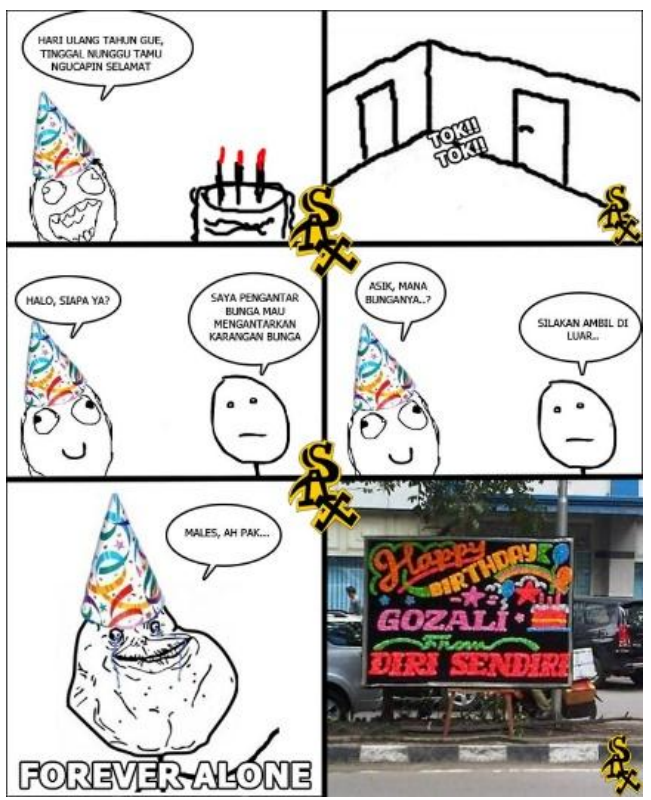

Panel 1: [balloon text] FAG: This is my birthday; I am just waiting for someone to congratulate me.

Panel 2: [text] knock! Knock!

Panel 3: [balloon text] FAG: Helo, who are you? | Derp: I'm a delivery man. There is a big bouquet just for you.

Panel 4: [ballon text] FAG: yeay, where is the bouquet? | Derp: Please take it outside.

Panel 5: [ballon text] FAG: I don't want to. FOREVER ALONE

Panel 6: [written on bouquet]: Happy birthday, Gozali! From myself.

Picture 13. "being lonely"
The comic strip above represents how FAG often comforts himself by sending a present for his own. The expression of this loneliness, therefore, can be seen as the outcome of the fact that there is no one who cares with him, even on his special day. The expression of comforting his own loneliness can also be seen in the next strip below,

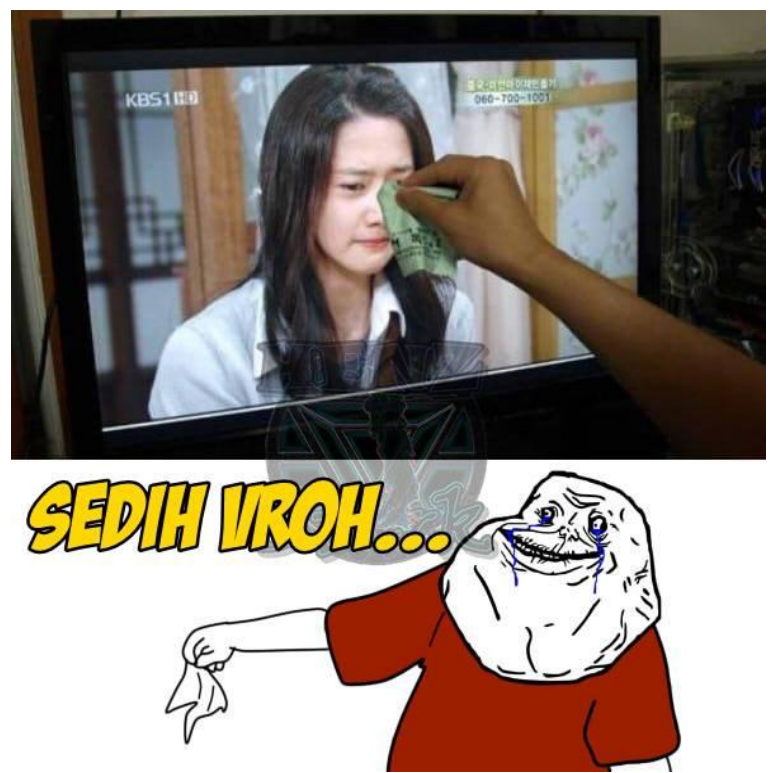

FAG: I'm sad, Vroh [slang].

Picture 14. "being lonely"

In the picture above, FAG shows the expression of comforting his own loneliness by watching a sad movie. He also sympathizes to the girl's feeling by wiping her tears. His action in wiping the girl onscreen is actually his way to express his own loneliness which has no company to watch a sad movie, and has no one to comfort. Therefore, he just comforts the girl on-screen's feeling.

The action of "comforting myself" is also one of the action that is done by most singles. Septiana and Syafiq (2013) stated by there are some ways that are done by singles in comforting themselves from the stigma and labels attached by the society to them. Some of the ways are thinking positively of their condition, taking a step back from people's preassure and giving up to destiny (79). However, in the representation of FAG, the actions of "comforting myself" are done through giving themselves a present or just watching romance drama. Although the actions of "comforting myself" are different, one basic thing that can be seen here is that singles always do something to comfort themselves from the pressures to "escape" from reality.

Lastly, the third expression done by FAG is by pretending to have a companion as can be seen below, 


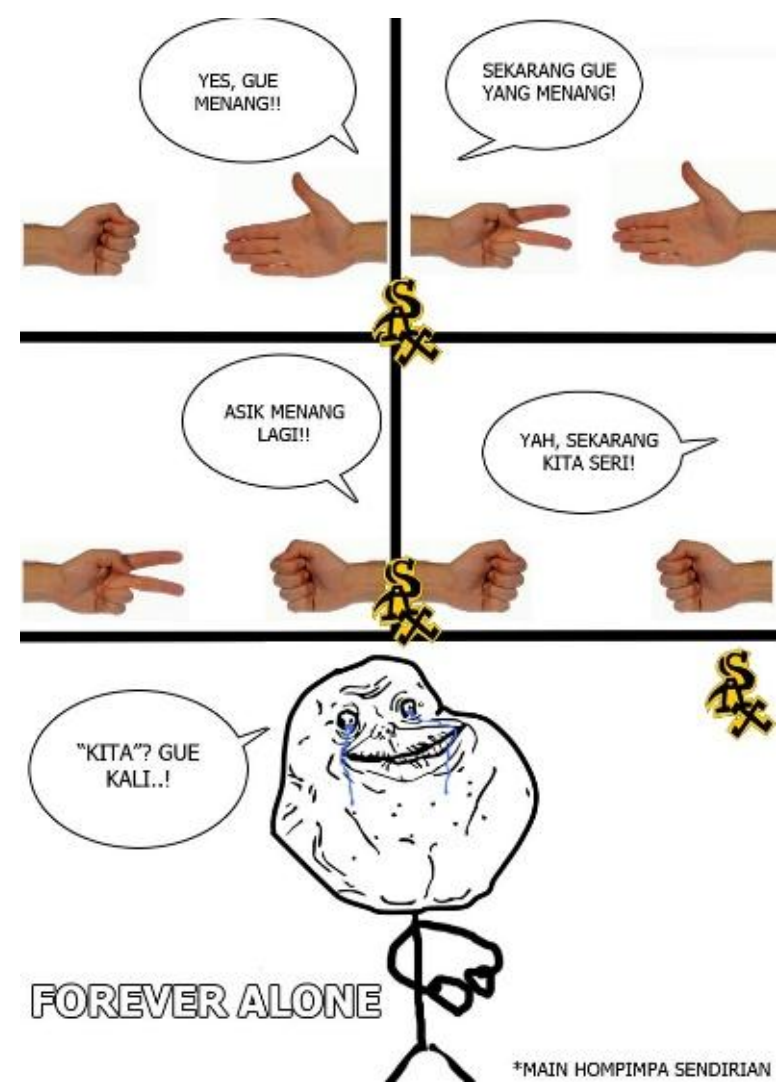

Panel 1: [balloon text] Hand 2: Yes, I win!

Panel 2: [balloon text] Hand 1: Now, I win!

Panel 3: [balloon text] Hand 2: Yeah, I win again!

Panel 4: [ballon text] Hand 2: Yah [interjection], now we are even.

Panel 5: [ballon text] FAG: "We are?" I myself. FOREVER ALONE

Picture 15: "being lonely"

In comic strips above, readers can see how FAG reacts to his loneliness, that is by playing with himself as if there is someone who plays with him. This point is also strengthened by the next picture below,

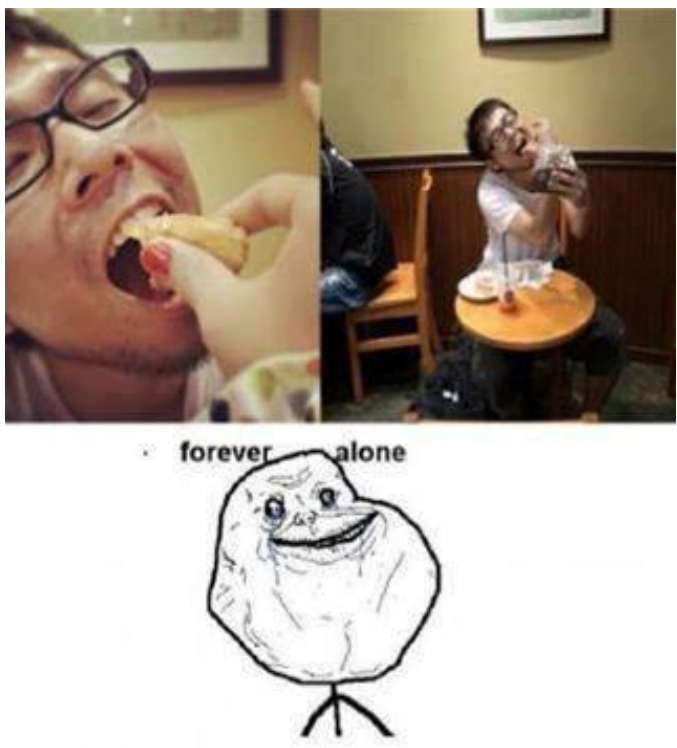

Picture 16. being lonely
When looking at picture 16 , readers may think that there is a girl's hand who gives the food to that boy. However, in the later panel, readers realize that actually that boy is doing the action by himself. This kind of representation draws an impression that FAG often expresses his loneliness by pretending to have a companion.

The representation of "playing with myself" here, shows that actually singles envy those who are in a relationship. Thus, they do silly things to express their jealousy. Tioso (1991) stated that one of negative behaviours shown by (female) singles is through showing their jealousy. They are jealous with the fact while the others are having someone to accompany their lives, they have no one (p.21). They show their jealousy by showing negative feeling to those who are in a relationship. However, in the representation of FAG, singles are shown as those who like to do silly things to mock at their condition. That is because FAG is in a format of comic strips which are made to entertain others, therefore, the impressions drawn from it are more into comedy.

Although the impression is more into comedy, the feeling of desperation shown in the plot is perfect enough to represent how singles see themselves as someone who is "lesser" than the rest of the society, and because they are "lesser, it is usual to mock one another through behaviour, speech, or etcetera.

Up to this point, I can say that FAG's loneliness is expressed through his actions which are imagining to be in love, comforting himself, and pretending to have a companion. Therefore, I can conclude that the mental representation of "lonely" here, is embedded with the similarities of negative representation from the text.

\section{CONCLUSION}

To sum up, FAG is represented negatively through mental representation of FAG as someone who is single, alone and lonely. This kind of representation is built from the cluster of negative stigmas or behaviours of FAG as a character. From the analysis, it can also be said that there are negative perspectives embedded to some elements in the comic strips such as characterization, plot, and even the way another character sees to the main character. This kind of representation, nevertheless, is affected by the 'dominant meanings' circulated among the society which believe that being 'single' and 'alone' are something that should be avoided since this status (of being single, alone and lonely) creates negative feelings like being 'inferior', 'selfish', or even 'aggressive'. That is why, most singles usually 
encounter the identity threat from the others (society) who believe and hold these stigmas tightly. Most people even pity them and encourage them to have a companion for themselves. From this data, it can be seen that although there is an increasing number of singles in Indonesia (Sample: there are over 103.568 female singles in Surabaya during 2010; 106.771 female singles in 2011; 108.659 singles in 2012) (Septiana \& Syafiq, 2013, p.72), it does not affect the strong position of the dominant meaning which creates the 'stigmas' attached to the singles as those who should be pitied of.

Moreover, this comic strip has a big influence toward the readers who access it online for their own entertainment, and even share it to the others. Through this medium, there is a possibility for a dominant meaning to spread its power and its perspectives to the other, even across the cultures or nations. Thus, it can be concluded that FAG is represented negatively in the comic strips by embedding negative stigma of the context within the text, and its medium has a big chance to spread its perspectives to the others through the online media.

\section{REFERENCES}

"Alone" (2016). Dictionary.com. LLC. Retrieved November 5 from http://www.dictionary.com/ browse/alone

"Lonely" (2016). Dictionary.com. LLC. Retrieved November 5 from http://www.dictionary.com/ browse/lonely

"Single" (2016). Dictionary.com. LLC. Retrieved November 5 from http://www.dictionary.com/ browse/single

Hall, Stuart (2013). Representation, second edition. United Kingdom: The Open University.

Kip (2010). Forever alone. Know your meme. Retrieved October 10 from http://knowyourmeme.com/memes/forever-alone

Septiana, Ema \& Syafiq, Muhammad (2013). Identitas "lajang" (single identity) dan stigma: studi fenomenologi perempuan lajang di Surabaya." Jurnal Psikologi Teori \& Terapan 2013, Volume 4, No.1, p. 71-86)

Tioso, K. Debora (1991). Perempuan yang tidak menikah, masalah dan tantangannya. Jakarta: PT. BPK. Gunung Mulia. 